STUDI

FRANCESI

\section{Studi Francesi}

Rivista quadrimestrale fondata da Franco Simone

185 (LXII | II) | 2018

OCTAVE MIRBEAU: UNE CONSCIENCE AU TOURNANT

DU SIEECLE - sous la direction de Ida Merello

\title{
OLIVIER GUERRIER, Rencontre et Reconnaissance. Les \\ "Essais" ou le jeu du hasard et de la vérité
}

\section{[Maurizio Busca]}

\section{(2) OpenEdition \\ Journals}

Édition électronique

URL : http://journals.openedition.org/studifrancesi/13501

DOI : 10.4000/studifrancesi. 13501

ISSN : 2421-5856

Éditeur

Rosenberg \& Sellier

Édition imprimée

Date de publication : 1 août 2018

Pagination : $314-315$

ISSN : 0039-2944

\section{Référence électronique}

[Maurizio Busca], " olivier guerrier, Rencontre et Reconnaissance. Les "Essais" ou le jeu du hasard et de la vérité », Studi Francesi [En ligne], 185 (LXII | II) | 2018, mis en ligne le 01 août 2018, consulté le 07 avril 2021. URL : http://journals.openedition.org/studifrancesi/13501 ; DOI : https://doi.org/10.4000/ studifrancesi. 13501

Ce document a été généré automatiquement le 7 avril 2021.

\section{(c)}

Studi Francesi è distribuita con Licenza Creative Commons Attribuzione - Non commerciale - Non opere derivate 4.0 Internazionale. 


\title{
OLIVIER GUERRIER, Rencontre et Reconnaissance. Les "Essais" ou le jeu du hasard et de la vérité
}

\author{
[Maurizio Busca]
}

\section{RÉFÉRENCE}

OLIVIER GUERRIER, Rencontre et Reconnaissance. Les "Essais" ou le jeu du hasard et de la vérité, Paris, Classiques Garnier, 2016, «Études montaignistes» 64, 294 pp.

1 Nel presente saggio, frutto di ricerche originali e della rielaborazione di materiali già pubblicati, Olivier Guerrier indaga i rapporti fra caso e verità, che considera come «phénomènes constituants» degli Essais, adottando un punto d'osservazione particolare. Il lavoro si fonda infatti sullo studio delle nozioni di rencontre e di reconnaissance in Montaigne, studio a partire dal quale l'A. sviluppa le sue riflessioni intorno alle questioni dell'«errance réfléchie» e del «dire vrai».

2 La prima parte del saggio («Montaigne et la "rencontre”», pp. 19-115) è dedicata all'analisi delle occorrenze della parola rencontre e dei suoi derivati negli Essais. Montaigne impiega la parola servendosi di tutto l'ampio ventaglio semantico di cui dispone nel xvi secolo, che rinvia, oltre che al lessico della guerra, agli ambiti della lingua (la parola vivace, l'«esprit»), del contingente e dell'inatteso. Le rencontres nell'opera di Montaigne sono considerate anche alla luce delle occorrenze che compaiono presso altri autori, come Amyot traduttore di Plutarco e Béroalde de Verville. Nella seconda parte («“La plume au vent...”. L’errance réfléchie», pp. 117-160), la nozione di rencontre viene messa più direttamente in relazione con quelle di caso e di occasione, che informerebbero l'etica stessa dell'autore quale emerge da un'opera in continua trasformazione e «qui résiste à toute systématisation» (p. 150). La terza parte («Les leçons du menteur, ou la parole juste», pp.161-207), solleva il problema della verità e di una parola che possa essere al contempo vera e falsa. Il capitolo muove dal 
celebre passo dell'Apologie in cui Montaigne evoca il paradosso del mentitore, per esplorare differenti modalità di «dire vrai»-o di «mentir vrai»: al centro di tali riflessioni troviamo, in particolare, la figura di Socrate, la nozione di parresia studiata da Michel Foucault e la categoria di plasma mutuata dalla retorica classica e dalla Seconda Sofistica. La quarta e ultima parte ("“Tout le monde me reconnoit en mon livre...". De la reconnaissance», pp. 209-260) si apre con una ricognizione dei diversi significati della parola reconnaissance e dei suoi campi di applicazione in Montaigne. L'A. sviluppa quindi una serie di proposte di lettura che, rifacendosi anche al modello del paradigma indiziario, intendono mostrare come il problema della reconnaissance sia una delle tensioni principali che attraversano un'opera «qui oscille entre le désir de la transparence des signes et le constat de leur opacité» (p. 264). 